Case Report

\title{
A Retroperitoneal Isolated Enteric Duplication Cyst Mimicking a Teratoma: A Case Report and Literature Review
}

\author{
Daichi Momosaka, ${ }^{1}$ Yasuhiro Ushijima, ${ }^{1}$ Akihiro Nishie, ${ }^{1}$ \\ Yoshiki Asayama, ${ }^{1}$ Kousei Ishigami, ${ }^{1}$ Yukihisa Takayama, ${ }^{2}$ \\ Daisuke Okamoto, ${ }^{1}$ Nobuhiro Fujita, ${ }^{1}$ Tetsuo Ikeda, ${ }^{3}$ Keiichiro Uchida, ${ }^{4}$ \\ Masaaki Sugimoto, ${ }^{5}$ Kenichi Kohashi, ${ }^{5}$ and Hiroshi Honda ${ }^{1}$ \\ ${ }^{1}$ Department of Clinical Radiology, Graduate School of Medical Sciences, Kyushu University, 3-1-1 Maidashi, Higashi-ku, \\ Fukuoka 812-8582, Japan \\ ${ }^{2}$ Department of Radiology Informatics and Network, Graduate School of Medical Sciences, Kyushu University, 3-1-1 Maidashi, \\ Higashi-ku, Fukuoka 812-8582, Japan \\ ${ }^{3}$ Center for Integration of Advanced Medicine and Innovative Technology, Graduate School of Medical Sciences, \\ Kyushu University, 3-1-1 Maidashi, Higashi-ku, Fukuoka 812-8582, Japan \\ ${ }^{4}$ Department of Medicine and Bioregulatory Science, Graduate School of Medical Sciences, Kyushu University, 3-1-1 Maidashi, \\ Higashi-ku, Fukuoka 812-8582, Japan \\ ${ }^{5}$ Department of Anatomic Pathology, Graduate School of Medical Sciences, Kyushu University, 3-1-1 Maidashi, Higashi-ku, \\ Fukuoka 812-8582, Japan \\ Correspondence should be addressed to Akihiro Nishie; anishie@radiol.med.kyushu-u.ac.jp
}

Received 5 September 2016; Accepted 27 November 2016

Academic Editor: Roberto Grassi

Copyright ( 2016 Daichi Momosaka et al. This is an open access article distributed under the Creative Commons Attribution License, which permits unrestricted use, distribution, and reproduction in any medium, provided the original work is properly cited.

\begin{abstract}
Enteric duplication cysts lacking anatomic association with the gastrointestinal tract are called isolated enteric duplication cysts (IEDCs). We present an atypical case of a retroperitoneal IEDC with a tortuous tubular complex shape that enfolded the surrounding retroperitoneal fat and mimicked a retroperitoneal teratoma. Multiplanar reconstruction images should be used to evaluate such a lesion correctly. A tortuous tubular complex shape could be a key finding to differentiate from other retroperitoneal cysts.
\end{abstract}

\section{Introduction}

Enteric duplication cysts (EDCs) are uncommon congenital anomalies that can be found anywhere along the alimentary tract from the tongue to the anus [1-4]. Essentially they are located in or immediately adjacent to some part of the alimentary tract wall [1]. Histologically, EDCs have a welldeveloped coat of smooth muscle and an epithelial lining that represents some portion of the intestinal tract mucosa and contain various concentrations of mucus [1]. The incidence rate of EDCs is 1 in every 4000 to 5000 live births [5]. Although the majority of cases are detected in infants, they can be found in patients of any age [6]. Some cases lack anatomic association with the normal gastrointestinal tract, and they are called isolated enteric duplication cysts (IEDCs) [7]. Prenatal vascular accidents, torsion, and heterotopic tumors may be considered the etiology of IEDCs [8]. This type of tumor has been reported in locations including the tongue $[1,2]$, pleural space $[1]$, liver $[9,10]$, pancreas $[1,11]$, biliary tree $[2,11,12]$, and retroperitoneum. Only 17 cases of retroperitoneal IEDCs are found in the literature [8, 13-27]. Most cases have a unilocular or multilocular shape.

Herein, we report a case of a retroperitoneal IEDC that formed a curious shape. This mass was misdiagnosed to 


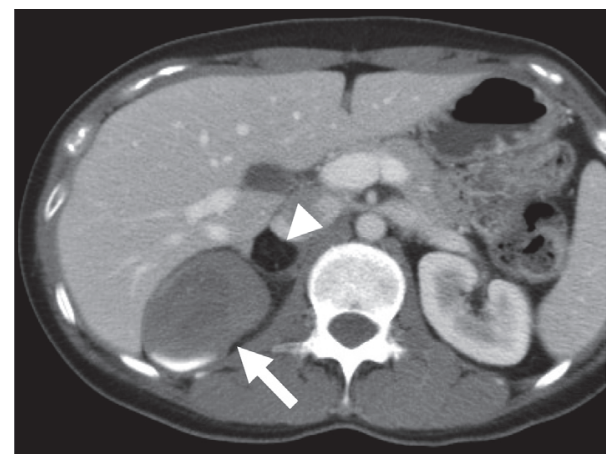

FIgURE 1: Axial contrast-enhanced CT scan. The mass consisted of a cystic component (arrow) and a nodular fatty component (arrowhead) at the right adrenal region. A high-density fluidfluid level was also seen in the cystic component. No enhancing component was observed.

include a fat component and was difficult to discriminate from a teratoma. We also discuss the radiological findings useful to a correct diagnosis of retroperitoneal IEDC.

\section{Case Presentation}

A 35-year-old woman visited our institution with an abdominal mass detected on abdominal ultrasound. The patient had no history of parity, drug use, or surgical intervention. On contrast-enhanced computed tomography (CT), a mass with a distorted shape and a diameter of $7.5 \mathrm{~cm}$ occupied the region between the right lobe of the liver and the right adrenal gland. The mass, which consisted of nodular fatty components, was well-circumscribed without contrast enhancement. A high-density fluid-fluid level was also seen (Figure 1). On magnetic resonance imaging (MRI), the cystic component showed heterogeneous high intensity on fatsuppressed T2-weighted images (Figure 2(a)) and relatively homogeneous isointensity compared to the muscle on T1weighted images (Figure 2(b)). On chemical shift images, microscopic fat was not observed in the cystic component. On DWI, the cystic component showed slightly high intensity and its ADC value was $2.0 \times 10^{-3} \mathrm{~mm}^{2} / \mathrm{sec}$, suggesting slightly restricted diffusion compared with the cerebrospinal fluid (Figure 2(c)). A nodular fatty component was again identified on MRI (Figures 2(a) and 2(b)). Based on the presence of a fatty component and possibly calcification or iodine inside the mass, our preoperative diagnosis was retroperitoneal teratoma. The patient underwent laparoscopic surgical intervention. Macroscopically, the mass was a tortuous tubular cyst. The nodular fatty component indicated on preoperative images was not a part of the mass but rather a part of the normal retroperitoneal fat that the complex cyst enfolded. The mass was separated from the colon and the right adrenal gland. Microscopically, the wall of the cyst consisted of welldeveloped smooth muscle and an epithelial lining representing the large-intestine mucosa. Its content was viscous mucus
(Figure 3). The final diagnosis was retroperitoneal IEDC. Retrospective multiplanar reconstruction (MPR) oblique images revealed the appearance of a tortuous tubular cyst clearly and showed that the nodular fat-density component of the mass was continuous with the normal retroperitoneal fat (Figure 4).

\section{Discussion}

EDCs are congenital enteric malformations with a cystic appearance, a well-developed coat of smooth muscle, and an epithelial lining representing some portion of the intestinal tract mucosa [28]. On CT and MRI, EDCs are wellcircumscribed fluid-filled cysts with a slightly enhanced thin wall, which is located in or adjacent to the normal gastrointestinal wall. The density and intensity of the intracystic fluid can vary depending upon mucous concentration, viscosity, and the existence of intermixed hemorrhage [29, 30]. In our case, the CT and MRI findings on the internal characteristics of the cystic component are consistent with those of the previous reports on EDCs.

The shape of the IEDC in our case is noteworthy. Only 17 cases of retroperitoneal IEDCs have been reported [8, 1327]. These cases are summarized in Table 1. Retroperitoneal IEDCs demonstrated unilocular (75\%) or multilocular to multilobulated (25\%) shapes. The present case is the first report of an IEDC with a tortuous tubular complex shape. However, in EDCs that have continuity with the wall of the normal alimentary tract, the shape can be either spherical $(80 \%)$ or tubular (20\%) [31]. That is, $20 \%$ of EDCs are tubular. It would be reasonable that IEDCs can also be tubular. To the best of our knowledge, this is the first reported case of a retroperitoneal cyst with such a shape [32].

Another point to discuss is that the mass enfolded surrounding retroperitoneal fat and mimicked a fat-containing tumor. A misdiagnosis resulting from that resemblance may derive from the tortuous tubular complex shape described above. Retrospectively, however, MPR images were useful for differentiating the IEDC from retroperitoneal teratoma because the nodular fat-density component of the mass was continuous with the normal retroperitoneal fat. In addition, MPR images also clearly revealed a tortuous tubular cyst. This image reconstruction technique is of great value for grasping the three-dimensional anatomy of a lesion [33]. For retroperitoneal masses, surgery is basically performed, although ultrasound-guided aspiration and ethanol sclerotherapy can be sometimes performed instead [34]. MPR images can enable surgeons to choose more appropriate operative methods.

In conclusion, a retroperitoneal IEDC can show a tortuous tubular shape and enfold surrounding retroperitoneal fat due to its complex shape. MPR images should be used to evaluate such a lesion correctly. A tortuous tubular complex shape could be a key finding to differentiate from other retroperitoneal cysts. 
TABLE 1: Retroperitoneal IEDCs.

\begin{tabular}{|c|c|c|c|c|c|c|c|c|}
\hline Case number & Age/sex & Laterality & Size $(\mathrm{cm})$ & Ectopic gastric mucosa & Ectopic pancreatic mucosa & Shape & Location & Ref. \\
\hline 1 & $19 \mathrm{y} / \mathrm{F}$ & $\mathrm{L}$ & 11 & + & - & Simple & Nearby pancreas & {$[13]$} \\
\hline 2 & $79 \mathrm{y} / \mathrm{F}$ & $\mathrm{L}$ & 5 & - & - & Simple & Left adrenal area & {$[14]$} \\
\hline 3 & $34 \mathrm{y} / \mathrm{F}$ & $\mathrm{R}$ & 10 & - & - & Simple & $\begin{array}{c}\text { Nearby } \\
\text { duodenum }\end{array}$ & {$[15]$} \\
\hline 4 & $19 \mathrm{y} / \mathrm{F}$ & $\mathrm{L}$ & 13 & - & - & Multilobular & ND & {$[16]$} \\
\hline 5 & $35 \mathrm{y} / \mathrm{F}$ & $\mathrm{L}$ & 5.5 & + & - & Polycystic & Left adrenal area & {$[17]$} \\
\hline 6 & $31 \mathrm{y} / \mathrm{F}$ & M & 5 & - & - & Simple & ND & {$[18]$} \\
\hline 7 & $1 \mathrm{wk} / \mathrm{ND}$ & $\mathrm{L}$ & 3.5 & ND & ND & Simple & ND & {$[19]$} \\
\hline 8 & $6 \mathrm{mo} / \mathrm{M}$ & $\mathrm{R}$ & 10 & ND & ND & Simple & ND & [19] \\
\hline 9 & $17 \mathrm{y} / \mathrm{M}$ & $\mathrm{L}$ & 8.6 & + & + & Simple & Left adrenal area & {$[20]$} \\
\hline 10 & $27 \mathrm{~d} / \mathrm{M}$ & $\mathrm{L}$ & 3 & + & - & Simple & Nearby pancreas & {$[21]$} \\
\hline 11 & $28 \mathrm{y} / \mathrm{F}$ & $\mathrm{L}$ & ND & + & - & Simple & $\begin{array}{c}\text { Nearby left } \\
\text { kidney }\end{array}$ & {$[22]$} \\
\hline 12 & $9 \mathrm{~d} / \mathrm{M}$ & M & 5 & + & - & Simple & Nearby pancreas & {$[23]$} \\
\hline 13 & $\mathrm{ND} / \mathrm{F}$ & Bil & 4 & - & - & Dumbbell & ND & {$[24]$} \\
\hline 14 & $7 \mathrm{mo} / \mathrm{F}$ & $\mathrm{R}$ & 2 & + & - & Polycystic & $\begin{array}{l}\text { Right adrenal } \\
\text { area }\end{array}$ & {$[25]$} \\
\hline 15 & $10 \mathrm{mo} / \mathrm{F}$ & $\mathrm{R}$ & 3.8 & + & - & Simple & Left adrenal area & {$[26]$} \\
\hline 16 & $9 \mathrm{mo} / \mathrm{M}$ & $\mathrm{R}$ & ND & + & ND & ND & $\begin{array}{l}\text { Nearby right } \\
\text { kidney }\end{array}$ & {$[27]$} \\
\hline 17 & $2 \mathrm{~d} / \mathrm{M}$ & $\mathrm{R}$ & 6 & - & - & Simple & $\begin{array}{c}\text { Nearby } \\
\text { extrahepatic bile } \\
\text { duct }\end{array}$ & [8] \\
\hline
\end{tabular}

IEDCs: isolated enteric duplication cysts, ND: not described, M: male, F: female, Bil: bilateral, R: right, L: left, M: middle, y: years, mo: months, wk: weeks, and d: days.

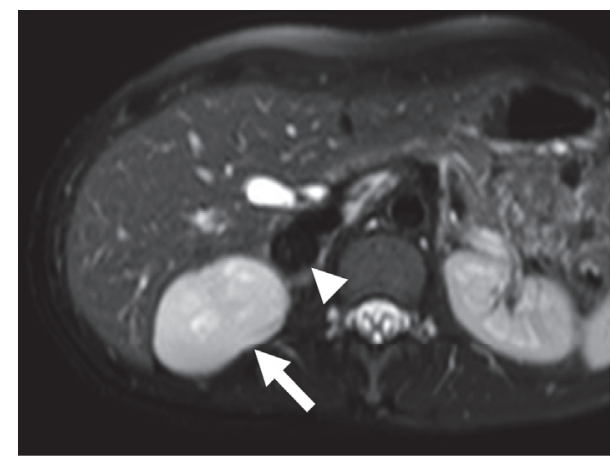

(a)

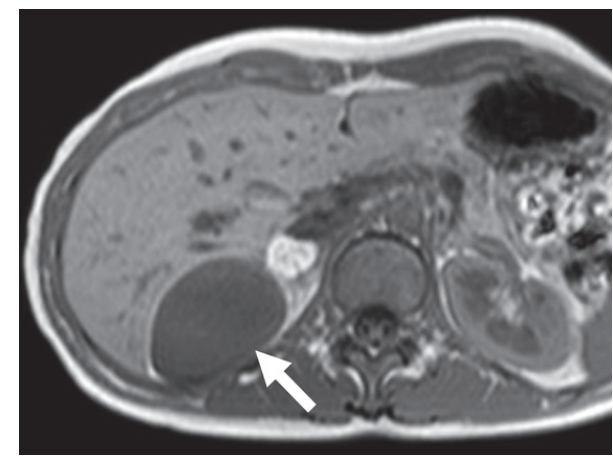

(b)

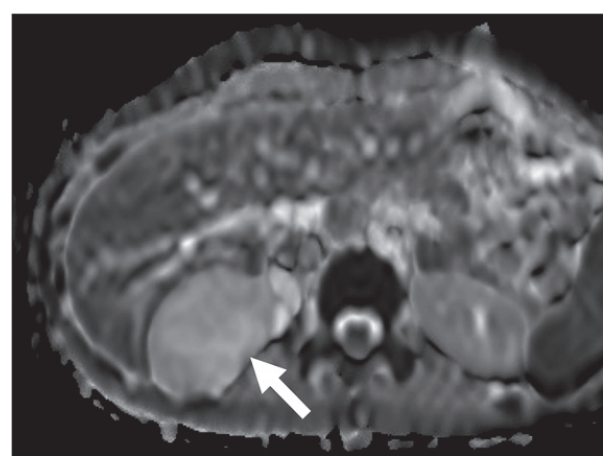

(c)

Figure 2: Axial MRI. (a) Fat-suppressed T2-weighted image showed heterogeneous high intensity inside the cystic component of the mass (arrow). The fatty component showed low intensity (arrowhead). (b) T1-weighted image showed relative homogeneous isointensity inside the cystic component of the mass (arrow). (c) ADC map showed slightly restricted diffusion compared with cerebrospinal fluid. Its ADC value was $2.0 \times 10^{-3} \mathrm{~mm}^{2} / \mathrm{sec}$. 


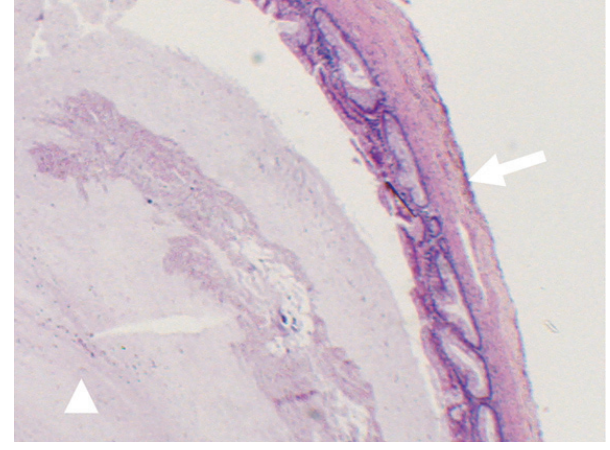

Figure 3: Microphotographs of the cystic wall. The wall consisted of large intestinal mucosa, submucosa, muscle layers, and serosa (arrow). The cyst was filled with viscous mucus (arrowhead). A cellular component was not seen (high magnification, hematoxylin and eosin staining).

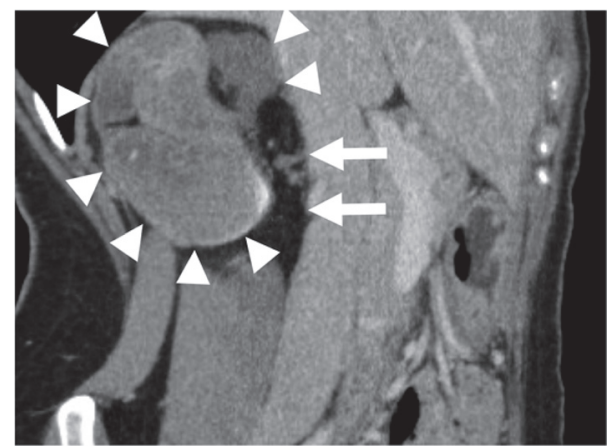

Figure 4: Oblique MPR images of contrast-enhanced CT scan. A tortuous tubular complex shape of the mass (arrowheads) was clearly observed. The nodular fatty component of the mass continued to the normal retroperitoneal fat (arrows).

\section{Competing Interests}

The authors declare that there is no conflict of interests regarding the publication of this paper.

\section{References}

[1] R. E. Gross, G. W. Holcomb, and S. Farber, "Duplications of the alimentary tract," Pediatrics, vol. 9, no. 4, pp. 448-468, 1952.

[2] B. E. Favara, R. A. Franciosi, and D. R. Akers, "Enteric duplications. Thirty-seven cases: a vascular theory of pathogenesis," American Journal of Diseases of Children, vol. 122, no. 6, pp. 501506, 1971.

[3] R. J. Bower, W. K. Sieber, and W. B. Kiesewetter, "Alimentary tract duplications in children," Annals of Surgery, vol. 188, no. 5, pp. 669-674, 1978.

[4] G. W. Holcomb III, A. Gheissari, J. A. O’Neill Jr., N. A. Shorter, and H. C. Bishop, "Surgical management of alimentary tract duplications," Annals of Surgery, vol. 209, no. 2, pp. 167-174, 1989.

[5] E. Gilbert Barness, Potter's Pathology of the Fetus, Infant and Child, Elsevier, Amsterdam, The Netherlands, 2nd edition, 2007.
[6] S. O. Choi, W. H. Park, and S. P. Kim, "Enteric duplications in children: an analysis of 6 cases," Journal of Korean Medical Science, vol. 8, no. 6, pp. 482-487, 1993.

[7] Z. Steiner and J. Mogilner, "A rare case of completely isolated duplication cyst of the alimentary tract," Journal of Pediatric Surgery, vol. 34, no. 8, pp. 1284-1286, 1999.

[8] R. Souzaki, S. Ieiri, Y. Kinoshita et al., "Laparoscopic resection of an isolated retroperitoneal enteric duplication in an infant," Journal of Pediatric Surgery Case Reports, vol. 1, no. 7, pp. 167170,2013

[9] K. H. Imamoglu and A. J. Walt, "Duplication of the duodenum extending into liver," The American Journal of Surgery, vol. 133, no. 5, pp. 628-632, 1977.

[10] J. D. Seidman, A. J. Yale-Loehr, B. Beaver, and C.-C. J. Sun, "Alimentary duplication presenting as an hepatic cyst in a neonate," American Journal of Surgical Pathology, vol. 15, no. 7, pp. 695-698, 1991.

[11] D. R. Akers, B. E. Favara, R. A. Franciosi, and J. M. Nelson, "Duplications of the alimentary tract: report of three unusual cases associated with bile and pancreatic ducts," Surgery, vol. 71, no. 6, pp. 817-823, 1972.

[12] K. Grumbach, D. H. Baker, J. Weigert, and R. P. Altman, "Biliary tract duplication cyst with gastric heterotopia," Pediatric Radiology, vol. 18, no. 4, pp. 357-359, 1988.

[13] N. Upadhyay, D. Gomez, M. F. Button, C. S. Verbeke, and K. V. Menon, "Retroperitoneal enteric duplication cyst presenting as a pancreatic cystic lesion. A case report," Journal of the Pancreas, vol. 7, no. 5, pp. 492-495, 2006.

[14] N. E. Terry, C. K. Senkowski, W. Check, and S. T. Brower, "Retroperitoneal foregut duplication cyst presenting as an adrenal mass," American Surgeon, vol. 73, no. 1, pp. 89-92, 2007.

[15] H. Hata, N. Hiraoka, H. Ojima, K. Shimada, T. Kosuge, and T. Shimoda, "Carcinoid tumor arising in a duplication cyst of the duodenum," Pathology International, vol. 56, no. 5, pp. 272-278, 2006.

[16] Y. S. Lo, J. S. Wang, C. C. Yu et al., "Retroperitoneal enteric duplication cyst," Journal of the Chinese Medical Association, vol. 67, pp. 479-482, 2004.

[17] R. D. Laraja, R. E. Rothenberg, J. Chapman et al., "Foregut duplication cyst: a report of a case," The American Journal of Surgery, vol. 61, pp. 840-841, 1995.

[18] H. Takiff, J. J. Brems, and M. L. Elliott, "Calcified retroperitoneal enteric duplication cyst," American Journal of Gastroenterology, vol. 88, no. 3, pp. 470-471, 1993.

[19] B. W. Duncan, N. Scott Adzick, and A. Eraklis, "Retroperitoneal alimentary tract duplications detected in utero," Journal of Pediatric Surgery, vol. 27, no. 9, pp. 1231-1233, 1992.

[20] P.-H. Chen, J.-Y. Lee, S.-F. Yang, J.-Y. Wang, J.-Y. Lin, and Y.-T. Chang, "A retroperitoneal gastric duplication cyst mimicking a simple exophytic renal cyst in an adolescent," Journal of Pediatric Surgery, vol. 45, no. 10, pp. e5-e8, 2010.

[21] T. Okamoto, S. Takamizawa, A. Yokoi, S. Satoh, and E. Nishijima, "Completely isolated alimentary tract duplication in a neonate," Pediatric Surgery International, vol. 24, no. 10, pp. 1145-1147, 2008.

[22] S. K. Kim, H. K. Lim, S. J. Lee, and C. K. Park, "Completely isolated enteric duplication cyst: case report," Abdominal Imaging, vol. 28, no. 1, pp. 12-14, 2003.

[23] N. Nakazawa, T. Okazaki, and T. Miyano, "Prenatal detection of isolated gastric duplication cyst," Pediatric Surgery International, vol. 21, no. 10, pp. 831-834, 2005. 
[24] D. A. May, S. E. Spottswood, M. Ridick-Young, and B. C. Nwomeh, "Case report: prenatally detected dumbbell-shaped retroperitoneal duplication cyst," Pediatric Radiology, vol. 30, no. 10, pp. 671-673, 2000.

[25] H. S. Bal, S. Kisku, S. Sen, and D. Masih, "A retroperitoneal enteric duplication cyst communicating with the right upper ureter in an infant," BMJ Case Reports, vol. 2014, 2014.

[26] M. Pachl, K. Patel, C. Bowen, and D. Parikh, "Retroperitoneal gastric duplication cyst: a case report and literature review," Pediatric Surgery International, vol. 28, no. 1, pp. 103-105, 2012.

[27] S.-F. Ko, S.-H. Ng, F.-C. Huang, M.-T. Sung, and C.-S. Hsieh, "Postprandial abdominal pain owing to isolated enteric duplication cyst in the superior mesenteric artery root: sonographic and magnetic resonance imaging features," Journal of Pediatric Surgery, vol. 46, no. 4, pp. 772-775, 2011.

[28] R. I. Macpherson, "Gastrointestinal tract duplications: clinical, pathologic, etiologic, and radiologic considerations," Radiographics, vol. 13, no. 5, pp. 1063-1080, 1993.

[29] T. Berrocal, M. Lamas, J. Gutiérrez, I. Torres, C. Prieto, and M. L. Del Hoyo, "Congenital anomalies of the small intestine, colon, and rectum," Radiographics, vol. 19, no. 5, pp. 1219-1236, 1999.

[30] R. L. Teele, C. I. Henschke, and D. Tapper, "The radiographic and ultrasonographic evaluation of enteric duplication cysts," Pediatric Radiology, vol. 10, no. 1, pp. 9-14, 1980.

[31] B. Domajnko and R. M. Salloum, "Duplication cyst of the sigmoid colon," Gastroenterology Research and Practice, vol. 2009, Article ID 918401, 3 pages, 2009.

[32] D. M. Yang, D. H. Jung, H. Kim et al., "Retroperitoneal cystic masses: CT, clinical, and pathologic findings and literature review," Radiographics, vol. 24, no. 5, pp. 1353-1365, 2004.

[33] M. M. Maher, M. K. Kalra, D. V. Sahani et al., "Techniques, clinical applications and limitations of $3 \mathrm{D}$ reconstruction in CT of the abdomen," Korean Journal of Radiology, vol. 5, no. 1, pp. 55-67, 2004.

[34] G. Gatta, V. Parlato, G. Di Grezia et al., "Ultrasound-guided aspiration and ethanol sclerotherapy for treating endometrial cysts," Radiologia Medica, vol. 115, no. 8, pp. 1330-1339, 2010. 


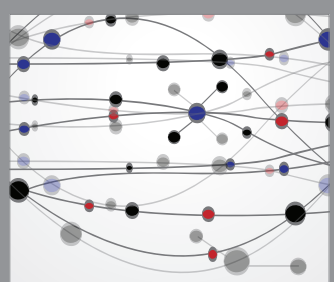

The Scientific World Journal
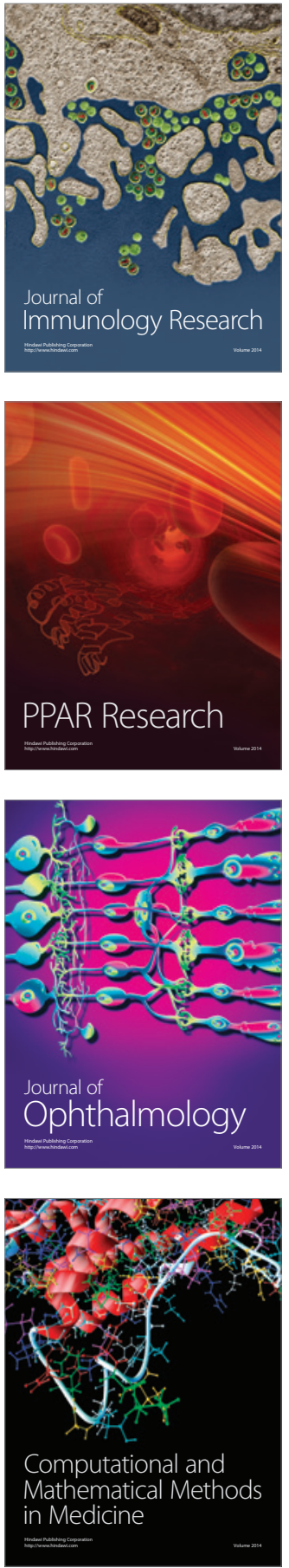

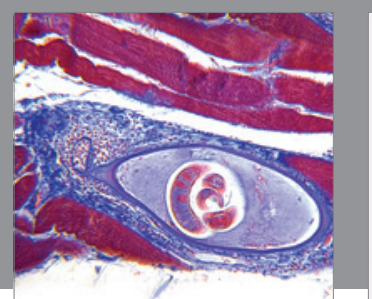

Gastroenterology Research and Practice

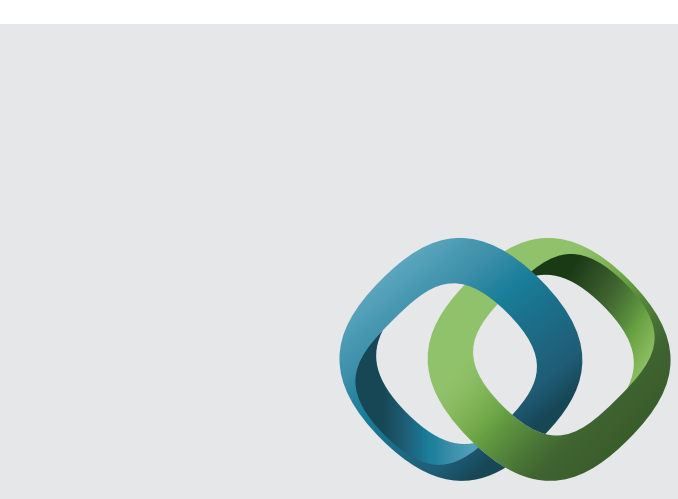

\section{Hindawi}

Submit your manuscripts at

http://www.hindawi.com
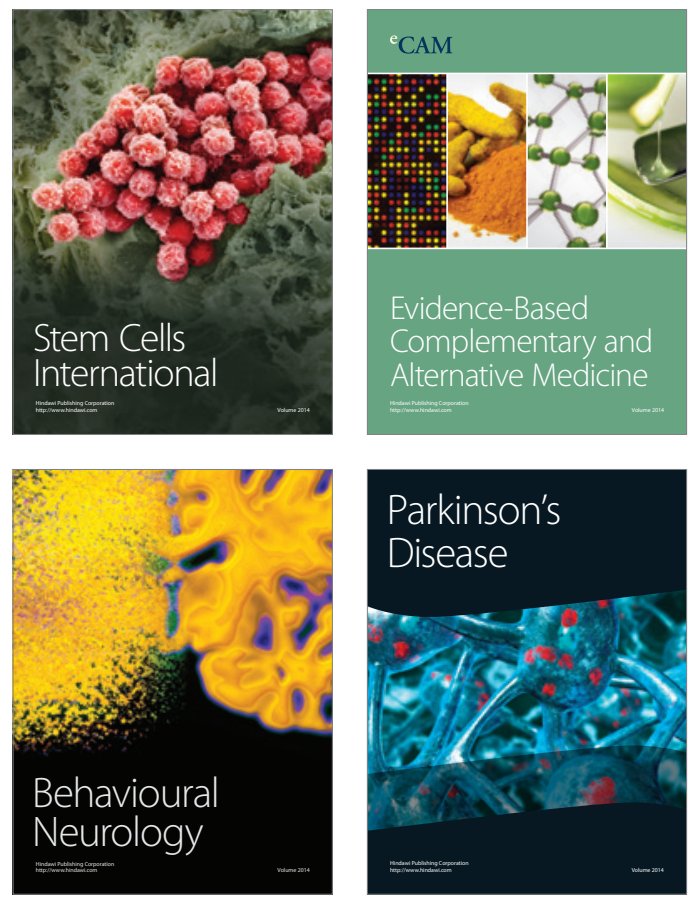
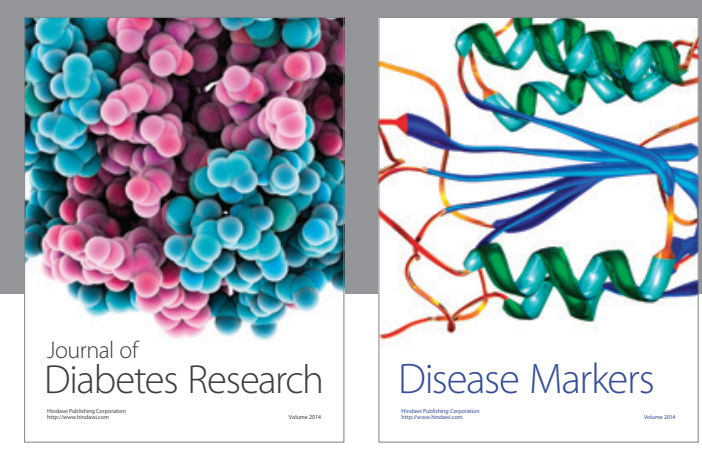

Disease Markers
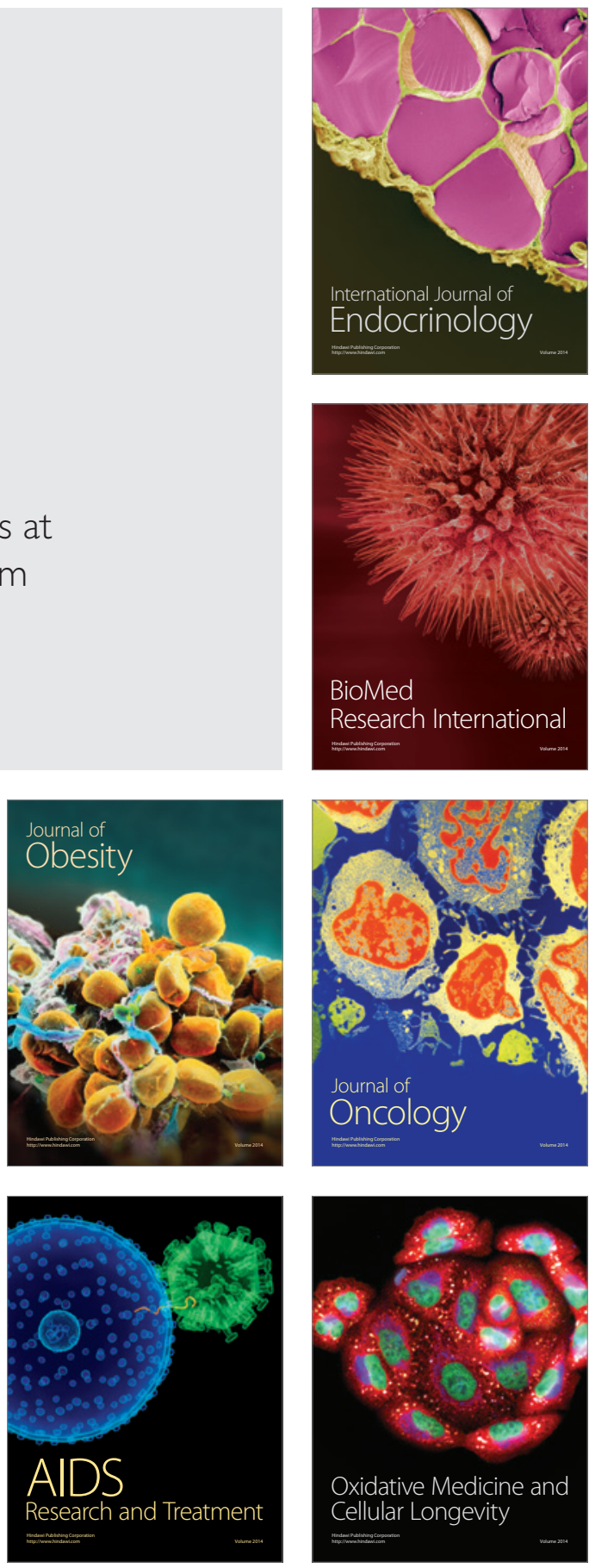